\title{
Incidence and Antibiotics Sensitivity of Multidrug-Resistance of Pseudomonas aeruginosa Isolated from Burn's Patients and Environmental Samples fromThree Hospitals in Baghdad

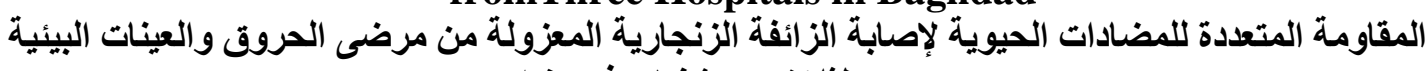

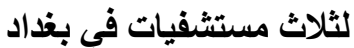

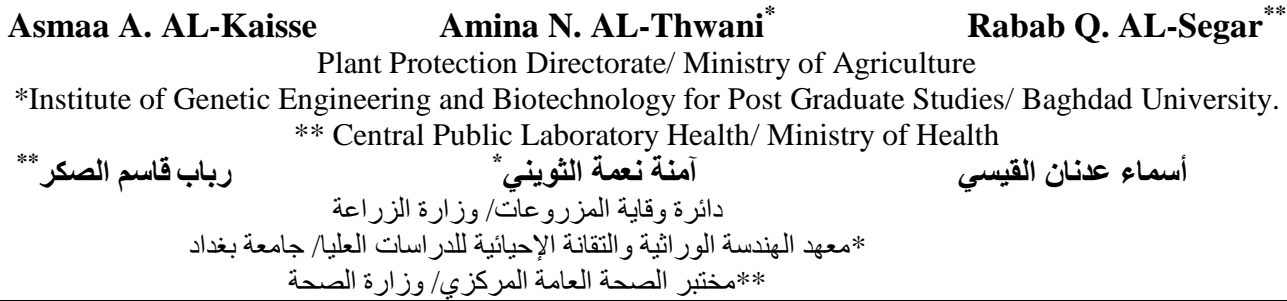

Abstract

Two hundred swab samples were collected from burn patients and burn units for the period, beginning from August 2012 to the end of April 2013 from a number of hospitals in Baghdad governorate including: Al-Kindi General Teaching Hospital, Al-Yarmuk General Teaching Hospital and Al-Imam Ali Hospital. The collected samples were cultured on different media and tested biochemically in order to find out the profile of bacteria that colonize burn patients wounds and environment of burn units. The results of bacterial culturing revealed that out of 200 samples, 105 samples $52.5 \%$ were observed to have bacterial growth (positive samples), while negative samples represented $95(47.5 \%)$. The profile of the bacteria in the cultured samples revealed: Pseudomonas aeruginosa $40.95 \%$ was the most common isolate followed by Staphylococcus aureus 20.0\%, Klebsiella pneumoniae 17.1\%, Escherichia coli 8.5\%, Pseudomonas putida 4.76\%, Enterobacter aerogenes $3.80 \%$, Acinetobacter baumannii $2.85 \%$ and Proteus mirabilis $1.90 \%$. Forty three $P$. aeruginosa isolates were tested for antibiotic susceptibility. The results showed most isolates were potentially resistant to different antibiotics as follow, all isolates $100 \%$ had resistance to Ceftriaxone, Cefepime, and Chloramphenicol, and showed high resistance to Tobramycin 95.3\%, Gentamicin 93.0\%, Ceftazidime 88.3\%, Cefotaxime 86.0\%, Piperacillin 83.7\% and Amikacin 79.0\%, beside illustrating low resistance to Aztreonam 67.4\%, Ciprofloxacin 46.5\%, and Imipenem 13.9\% among these antibiotics, Imipenem was the most effective antibiotic because $86.0 \%$ of the isolates appeared to be high sensitive to it.

Key words: Antibiotics Sensitivity of Multidrug-Resistance, Pseudomonas aeruginosa, Burn's Patients

جمعت مائتي مسحة من مرضى الحروق ووحدات الحروق للفترة من بداية آب 2012 إلى - نهاية نيسان 2013 من عدد من المستشفيات في

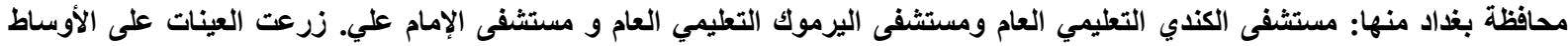

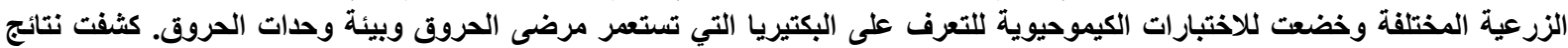

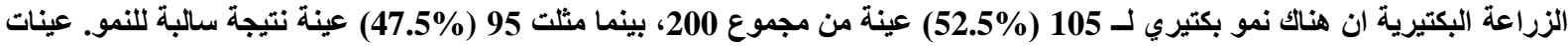

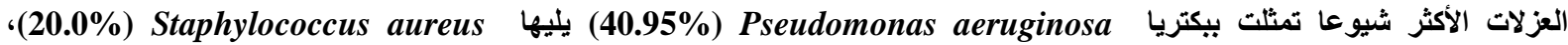
Enterobacter ،(4.76\%) Pseudomonas putida ،(8.5\%) Escherichia coli ،(17.1\%) Klebsiella pneumoniae عزلات Acinetobacter baumannii ، (3.80\%) aerogenes

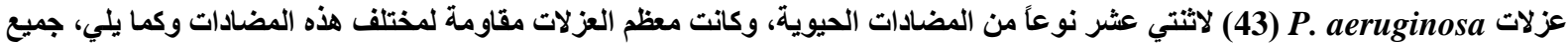

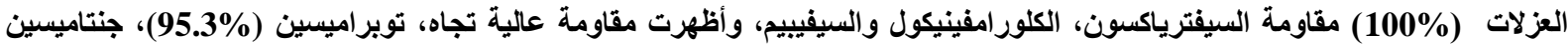

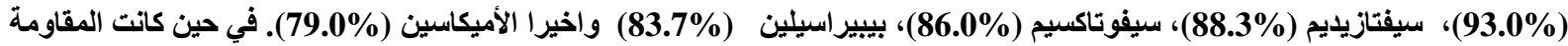

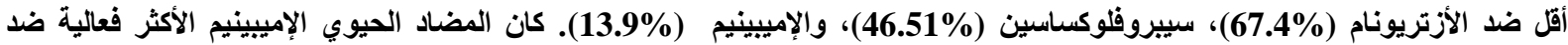

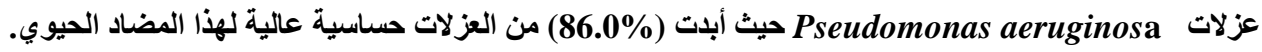

الكلمات المفتاحية: المقاومة المتعددة للمضادات الحيوية، الزائفة الزنجارية، مرضى الحروق.

Introduction

Infections are the major cause of morbidity and mortality in burn patients. Three fourth of deaths in burn patients occur due to infections. Skin is one of the largest organs in the body, performs numerous vital functions, including fluid homeostasis, thermoregulation, immunologic functions, neuro sensory functions, and metabolic functions (e.g., vitamin D) [1]. Skin also provides primary protection against infection by acting as a physical barrier, when this barrier is damaged; pathogens have a direct route to infiltrate the body, possibly resulting in 
infection [2]. Burns provide a suitable site for bacterial multiplication. Moreover the larger area of tissue is exposed for a longer time that renders patients prone to invasive bacterial sepsis [1]. The pathogens that infect the wound are primarily gram-positive bacteria such as methicillin-resistant Staphylococcus aureus (MRSA) and gram-negative bacteria such as complex, Pseudomonas, and Klebsiella species. These latter pathogens are notable for their increasing resistance to a broad array of different antimicrobial agents [3]. The risk of infections in burns is well known, available current techniques of burn wound care have significantly decreased the incidence of infections in patients with burn wounds [4]. Gram-negative pathogens continue to cause the most severe infections in burn's patients. Among these organisms, P. aeruginosa is the most commonly encountered source of chronic or acute burn wound infection in the United States [5]. In Europe, P. aeruginosa and E. coli are the two most common pathogens, with a frequency for each at $13 \%$ of all gram-negative infections [6]. In recent years, emerging resistant pathogens have forced burn care providers worldwide to search for alternative forms of treatment. Multi-drug resistant S. aureus, P. aeruginosa, Acinetobacter spp., and various fungal strains have been the major contributors to the increase in morbidity and mortality rates [5, 6]. Microorganisms routinely isolated from burn injuries and wounds include aerobic organisms like P. aeruginosa, S.aureus, E.coli ...etc. according to data from various medical records in different countries, the epidemiology of the pathogens of burn wounds is represented by: P.aeruginosa (25. 74\%), S.aureus $(9.17 \%)$, E. coli (5.35\%) ..etc [7]. In Iraq, Alwan [8] studied the bacteria of burns wounds and their antimicrobial susceptibility; it was found P. aeruginosa the most common isolate, followed by $S$. aureus. Pseudomonas aeruginosa was the most commonly gramnegative bacilli isolated from burns, followed by E. coli, Enterobacter spp., Klebsiella spp.and Proteus spp. This study was conducted to determine the incidence of Pseudomonas aeruginosa infections and sensitivity of antibiotic among burn patients for nine months. Burns are injuries to tissues caused by heat, electricity, radiation or other factors [9].

\section{The Aim of Study}

This study was conducted to determine the incidence of $P$. aeruginosa infections and sensitivity of antibiotic among burn patients.

\section{Materials and Methods Collection of Samples}

This study last for nine months starting from August 2012, till April 2013. The clinical swaps were collected from 100 burn's patients in three hospitals in Baghdad, Al-Kindi General Teaching Hospital 59 swabs, AlYarmuk General Teaching Hospital 22 swabs and Al-Imam Ali Hospital 19 swabs. Population of study included both gender with different age started with younger patients who were one year old and ended with oldest patients who were seventy one years old, admitted patients came from different geographic residencies, and one hundred environmental swabs were taken from equipments of burn's units: gloves, beds, floors, benches, walls and washing baths from different hospitals as following: 40 swabs from Al-Kindi General Teaching Hospital, 40 swabs from Al-Yarmuk General Teaching Hospital and 20 swabs from Al-Imam Ali Hospital.

\section{Isolation of Bacteria}

Pseudomonas aeruginosa, Staphylococcus aureus, Klebsiella pneumonia, Escherichia coli, Pseudomonas putida, Enterobacter aerogenes, Acinetobacter baumannii and Proteus mirabilis were isolated from 200 samples which isolated from burn's patients skin and burn's units equipments of the three hospitals in Baghdad/ Iraq. All collected swabs were cultured on MacConkey agar and Blood agar, incubated aerobically at $37^{\circ} \mathrm{C}$ for $24 \mathrm{hr}$ and citrimide agar at $42^{\circ} \mathrm{C}$ [10]. Only the cultured swabs which gave growth on these media were estimated to have positive results.

\section{Identification of Bacterial Isolates}

Staphylococcus aureus grew on mannitol salt agar which was a selective medium, isolated and identified biochemically, and gave positive results for catalase and coagulase tests and by API Staph. All gram negative bacteria identified by traditional biochemical tests and API 20 E including K. pneumonia, E .coli, P. putida, E. aerogenes and A. baumannii,. Pseudomonas aeruginosa isolates were identified by traditional biochemical tests including Oxidase, Catalase, IMVC, Citrate utilization, Urease Production, Motility, Growth on Citrimide Agar and growth at $42^{\circ} \mathrm{C}$. In addition to these tests, Sugar fermentation tests including Glucose, Sucrose, Maltose, and by API $20 \mathrm{E}$ standardized identification system were also performed [10]. In this study we used 12 antibiotics susceptibility testing by a standardized single disk method as previously published by [11]. Gram stain bacteria was significantly higher than positive in both burn's patients and burn's units. 


\section{Results and Discussion}

The results of bacterial culture obtained from 100 burn's patients admitted by the three hospitals clarified that, 67 (67\%) gave positive result while $33(33 \%)$ gave negative result. Thirty three percentages $33 \%$ of cases showed negative culturing that may be due to either patients have antibiotics treatment swabs were obtained from new burns because burn surfaces were initially sterile, but within $48 \mathrm{hr}$ the wound was typically colonized by microorganisms [12]. The present study revealed that 40(59.7\%) from total positive culture showed single bacterial isolate while the results clarified that, $P$. aeruginosa was the commonest isolate (28 isolates; $41.8 \%$ ) followed by $S$. aureus (13 isolates; 19.4\%), K. pneumonia (12 isolates; $18 \%$ ), E .coli (6 isolates; $8.9 \%$ ), P. putida (3 isolates; $4.5 \%$ ). Both E. aerogenes and A. baumannii were 2 isolates for each $(3.0 \%)$, and P. mirabilis the lowest isolated microorganisms which only account for one (1.5\%), Table (1) and Figure (1) represent $P$. eruginosa isolate cultured on Cetrimide Agar.

Table (1): Types of Clinical Isolates From Burn's Patients Wounds.

\begin{tabular}{lcc}
\multicolumn{1}{c}{ Pathogens isolation } & $\begin{array}{c}\text { Total } \\
\text { Viable Count }\end{array}$ & $\begin{array}{c}\text { Percentage } \\
(\%)\end{array}$ \\
\hline Pseudomonas eruginosa & 28 & 41.8 \\
Staphylococcus aureus & 13 & 19.4 \\
Klebsiella pneumonia & 12 & 18.0 \\
Escherichia coli & 6 & 8.9 \\
Pseudomonas putida & 3 & 4.5 \\
Enterobacter aerogenes & 2 & 3.0 \\
Acinetobacter aumannii & 2 & 3.0 \\
Proteus mirabilis & 1 & 1.5 \\
\hline \multicolumn{1}{c}{ Total No. } & 67 & 100.1 \\
\hline
\end{tabular}

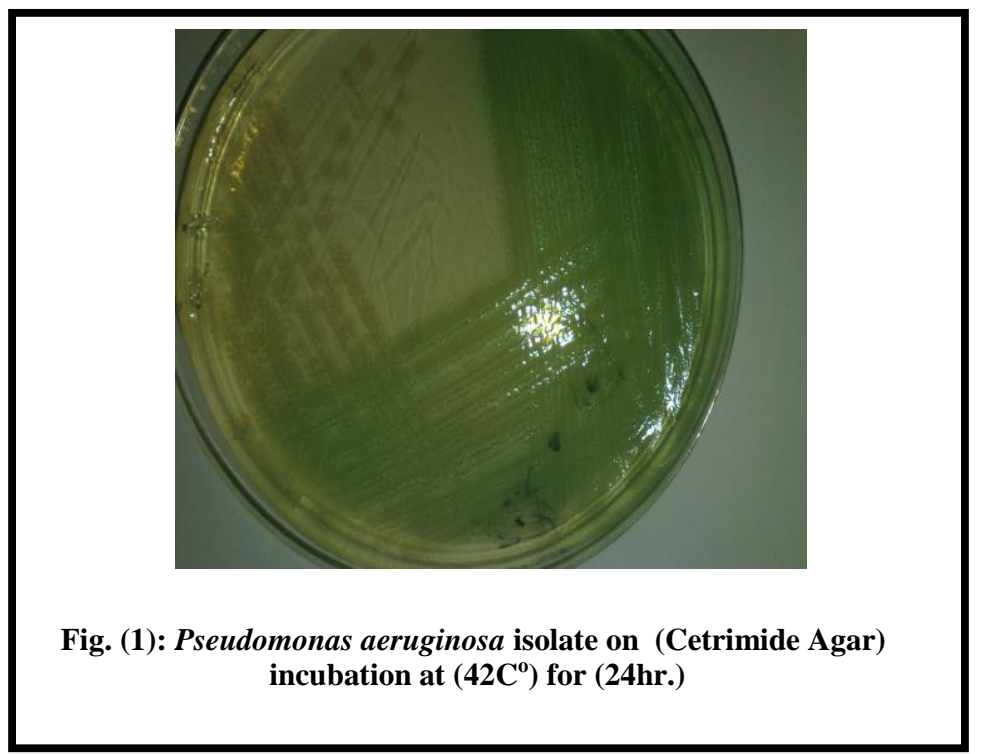

API 20 E system used for confirmation the diagnosis of $P$.aeruginosa isolates. Figure (2) Showed biochemical reactions of these bacteria after $24 \mathrm{hr}$ at $37^{\circ} \mathrm{C}$.

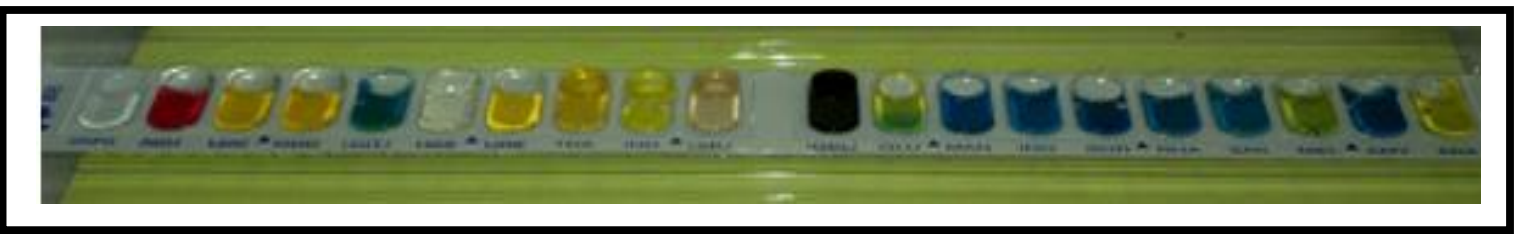

Fig. (2): Biochemical identification of Pseudomonas aeruginosa using API 20E system incubated in $(24 \mathrm{hr})$ at $\left(37^{\circ} \mathrm{C}\right)$

The cultural results of 100 environmental swabs collected from burn's units equipments (gloves, beds, floors, benches, walls and washing baths) from the three hospitals, revealed that 38 (38\%) of swabs gave positive result for bacterial growth and the rest $62(62 \%)$ were negative. The predominant bacteria was $P$. aeruginosa $(39.50 \%)$, 
followed by $S$. aureus $(21.0 \%)$ while $K$. pneumoniae came third (15.7\%), then E. coli (7.8\%), P. putida, E. aerogenes recovered in similar rate $(5.26 \%)$, the least isolated microorganism were $A$. baumannii and $P$. mirabilis as $(2.63 \%)$ for each, Table (2).

Table (2): Types of Environmental Isolates from Burn's Units Equipments.

\begin{tabular}{lcc}
\multicolumn{1}{c}{ Isolate } & $\begin{array}{c}\text { Total } \\
\text { Viable } \\
\text { Count }\end{array}$ & $\begin{array}{l}\text { Percenta } \\
\text { ge }(\%)\end{array}$ \\
\hline Pseudomonas aeruginosa & $\mathbf{1 5}$ & $\mathbf{3 9 . 5}$ \\
Staphylococcus aureus & $\mathbf{8}$ & $\mathbf{2 1 . 0}$ \\
Klebsiella pneumonia & 6 & 15.7 \\
Escherichia coli & $\mathbf{3}$ & $\mathbf{7 . 8}$ \\
Pseudomonas putida & $\mathbf{2}$ & $\mathbf{5 . 2 6}$ \\
Enterobacter aerogenes & $\mathbf{5 . 2 6}$ \\
Acinetobacter baumannii & 1 & $\mathbf{2 . 6 3}$ \\
Proteus mirabilis & 1 & $\mathbf{2 . 6 3}$ \\
\hline \multicolumn{1}{c}{ Total No. } & 38 & $\mathbf{1 0 0}$ \\
\hline
\end{tabular}

The results of bacterial culturing revealed that out of 200 samples isolates from burn's patients and burn's units equipments, 105 samples (52.5\%) were observed to have bacterial growth (positive samples), while negative samples represented (47.5\%). Gram positive bacteria were observed in $19.4 \%$ of clinical isolates, while the corresponding percentage of environmental isolates was $21.0 \%$. The remaining samples were represented G-ve bacteria and their percentage in Clinical isolates and environmental isolates were $80.6 \%$ and $79.0 \%$, respectively . The number of negative Gram stain bacteria was significantly higher than positive in both burn's patients and burn's units $(\mathrm{P} \leq 0.001)$ as illustrated in Table (3).

Table (3): Distribution of (G+ve) and (G-ve) Bacteria of Clinical and Environmental Isolates.

\begin{tabular}{|c|c|c|c|c|c|c|c|c|}
\hline \multirow{3}{*}{ Samples } & \multicolumn{4}{|c|}{ Total Viable Count } & \multirow{2}{*}{\multicolumn{2}{|c|}{ Total No. (\%) }} & \multirow{3}{*}{$\mathbf{X}^{2}$} & \multirow{3}{*}{$\mathbf{P}$} \\
\hline & \multicolumn{2}{|c|}{$\mathbf{G + v e}$} & \multicolumn{2}{|c|}{ G-ve } & & & & \\
\hline & No. & $\%$ & No. & $\%$ & No. & $\%$ & & \\
\hline Clinical isolates & 13 & 19.4 & 54 & 80.6 & 67 & $\overline{100.0}$ & 17.655 & $<0.001$ \\
\hline Environmental isolates & 8 & 21.0 & 30 & 79.0 & 38 & 100.0 & 13.564 & $<0.001$ \\
\hline
\end{tabular}

Cultural evaluation of samples with a growth of aerobic bacteria revealed that there were eight main pathogens (P. aeruginosa, S. aureus, K. pneumoniae, E. coli, P. putida, E. aerogenes, A. baumannii, and P. mirabilis), which were isolated and identified. Such distribution was different with the source of sample (burn's patients and burn's units) was considered. It was found that the $P$. aeruginosa consist $41.8 \%$ of clinical isolate (burn's patients) and $39.5 \%$ of environmental isolates (burn's units), followed by S. aurous $19.4 \%$ of clinical isolates and $21 \%$ of environmental isolates and so on as demonstrated in Table (4).

Table (4): Identification Percentages of Bacterial Isolates from Cultured Burn's Patients and Environment Burn's Units Samples.

In this study, $P$. aeruginosa was found to be the most incidence bacterium in burn's patients and burn's units, so this result was expected since this bacterium is resistant to many antibiotics and antiseptics. This bacteria occurs so commonly in the environment making it extremely likely that an individual suffering severe burns or contaminated of environment burn's units will be challenged with this opportunistic microorganism before the burn can heal [13]. Pseudomonas aeruginosa has been found to contaminate the floors, bed rails and sinks of hospitals, and has been also cultured from the hands of nurses [14]. Besides transmission through vomits and vectors, bacterial flora can be carried into a hospital by the patients and can be an important source of infection 
for the same individual after incineration [15]. These potential pathogens typically come from the patients gastrointestinal tract, upper respiratory tract, or the hospital environment, transferring through contact with health care workers. Fungal infections often develop later [2]. Pseudomonas aeruginosa survives well in the hospital environment, once it was established, it can persist for months within a unit, posing as Multi drug resistant nosocomial infection risk for patients being treated [16]. Hands of staff members can become transiently contaminated and transfer infection among patients that play important role in increase chance of spreading this microorganisms [17], also this high frequency of $P$. aeruginosa might be due to prolonged hospital stay and intensive use of antibiotics [18]. Staphylococcus aureus emerged as a second pathogen was isolated with $20.0 \%$ of total isolates this does not coincidence with the findings of Al-Khazali who found gram positive bacterium $S$. aureus (57.6\%) was the most incidence in burn's patients and burn's units [19]. Klebsiella pneumoniae was obtained from burn's patients and environment burn's units with percentage of $17.1 \%$, this result coincidence with Al-Shamary who found it was $(22.4 \%)$ the second most common isolate in burn's injuries and units [20]. Proteus mirabilis found in percentage of $1.90 \%$ and that similar to results which reported $P$. mirabilis with $2.1 \%$ [20]. The variations among studies in the type and the rate of bacterial isolation from burn's patients and environment burn's units may be due to the varies of infective agents spectrum from time to time and from place to place. Also these variations effected by patient hospitalization period. Also antimicrobial susceptibility was performed to 43 P.aeruginosa isolates of 12 antibiotics, 7 of them were extended spectrum beta lactamase (ESBLs) represented by Cefotaxime, Ceftriaxone, Ceftazidime, Imipenem, Aztreonam, Piperacillin and Cefepime, and to 5 antibiotics were non ESBLs represented by Aminoglycoside (Amikacin, Gentamicin and Tobramycin), Chloramphenicol and Fluoroquinolone (Ciprofloxacin), by the disc diffusion method (DDM), as described by [11]. The antibiogram for studied isolates was revealed that all isolates (100\%) resist to Ceftrixone, Cefepime, and Chloramphenicol and this resistance became 95.3 and $95.3 \%$ against Tobramycin and Gentamicin, while reached to 93.0 , 88.3 and 86.0\% against Ceftazidime, Cefotaxime and Piperacillin respectively, followed by $81.3 \%$ for Amikacin and lower resistance $67.4 \%$ and $48.8 \%$ for Aztreonam and Ciprofloxacin respectively, Imipenem was the most effective antibiotic $86.0 \%$ of isolates appeared to be high sensitive to it. Pseudomonas aeruginosa was becoming resistant to commonly used antibiotics and gaining more and more resistance to newer antibiotics [12]. This study found that Imipenem is the drug of chose in treatment of $P$. aeruginosa burn injury, because $86.0 \%$ of isolates were susceptible to it and only six isolate were exhibit resistance, as illustrated in Table (5) and Figure (3) represent susceptibility patteren of P. eruginosa against various antibiotics.

Table (5): Antibiotic Susceptibility of Pseudomonas aeruginosa Isolates.

\begin{tabular}{|c|c|c|c|c|c|c|c|}
\hline \multicolumn{8}{|c|}{$P$. aeruginosa isolates of total number viable count $=43 \mathrm{q} 2$} \\
\hline \multirow{2}{*}{ Antibiotics } & \multirow{2}{*}{$\begin{array}{c}\text { Disk } \\
\text { Content }\end{array}$} & \multicolumn{2}{|c|}{ Resistant } & \multirow{2}{*}{$\begin{array}{c}\text { Zone diameter } \\
(\mathbf{m m})\end{array}$} & \multicolumn{2}{|c|}{ Sensitive } & \multirow{2}{*}{$\begin{array}{c}\text { Zone } \\
\text { diameter } \\
(\mathbf{m m})\end{array}$} \\
\hline & & $\begin{array}{c}\text { No. of } \\
\text { Bacteria }\end{array}$ & $\%$ & & $\begin{array}{r}\text { No. of } \\
\text { Bacteria }\end{array}$ & $\%$ & \\
\hline Cefotaxime & $30 \mu \mathrm{g}$ & 38 & 88.3 & $\leq 14$ & 5 & 11.6 & $\geq 23$ \\
\hline Ceftrixone & $30 \mu \mathrm{g}$ & 43 & 100.0 & $\leq 13$ & - & - & $\geq 21$ \\
\hline Ceftazidime & $30 \mu \mathrm{g}$ & 40 & 93.0 & $\leq 14$ & 3 & 6.9 & $\geq 18$ \\
\hline Imipenem & $10 \mu \mathrm{g}$ & 6 & 13.9 & $\leq 13$ & 37 & 86.0 & $\geq 16$ \\
\hline Aztreonam & $30 \mu \mathrm{g}$ & 29 & 67.4 & $\leq 15$ & 14 & 32.5 & $\geq 22$ \\
\hline Amikacin & $30 \mu \mathrm{g}$ & 35 & 81.3 & $\leq 14$ & 8 & 18.6 & $\geq \mathbf{1 7}$ \\
\hline Gentamicin & $10 \mu \mathrm{g}$ & 41 & 95.3 & $\leq 12$ & 2 & 4.6 & $\geq 15$ \\
\hline Ciprofloxacin & $5 \mu \mathrm{g}$ & 21 & 48.8 & $\leq 15$ & 22 & 51.1 & $\geq 21$ \\
\hline Piperacillin & $100 \mu \mathrm{g}$ & 37 & 86.0 & $\leq \mathbf{1 7}$ & 6 & 13.9 & $\geq 18$ \\
\hline Cefepime & $30 \mu \mathrm{g}$ & 43 & 100 & $\leq 14$ & - & - & $\geq 18$ \\
\hline Chloramphenicol & $30 \mu \mathrm{g}$ & 43 & 100 & $\leq 12$ & - & - & $\geq 18$ \\
\hline Tobramycin & $10 \mu \mathrm{g}$ & 41 & 95.3 & $\leq 12$ & 2 & 4.6 & $\geq 21$ \\
\hline
\end{tabular}




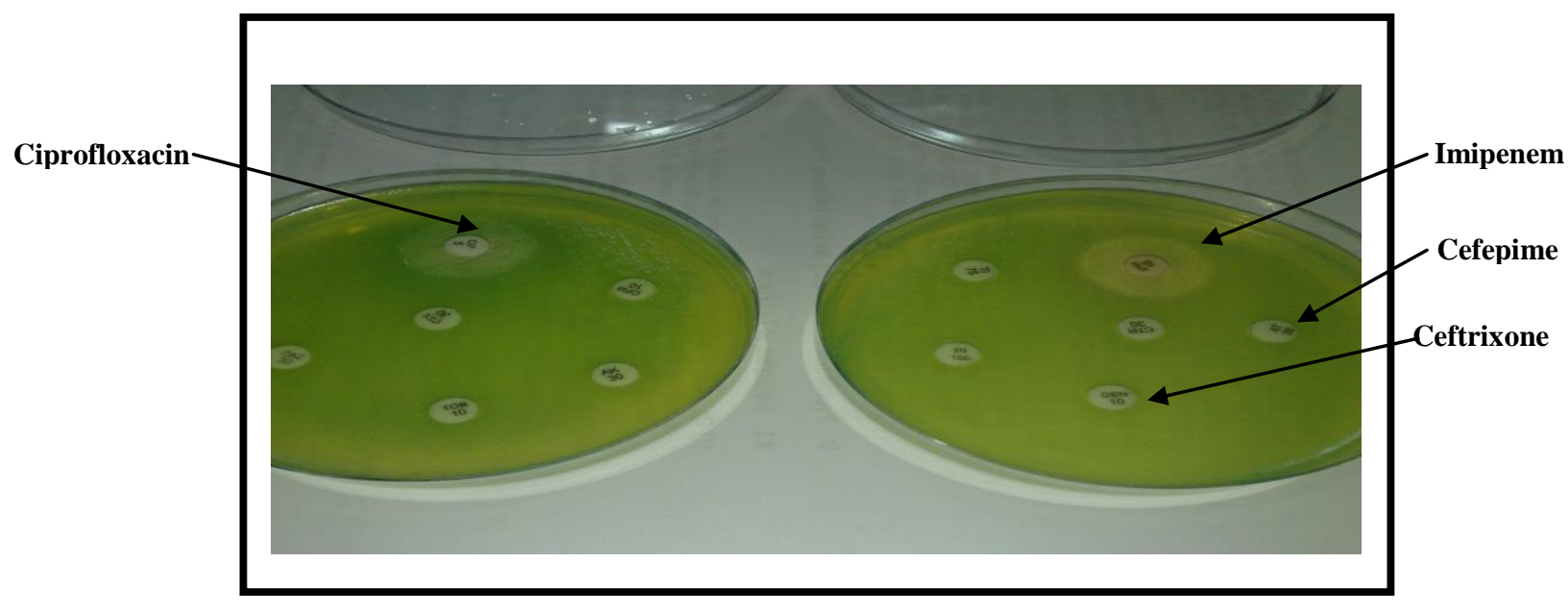

Fig. (3): Susceptibility Pattern of $P$. aeruginosa against various antibiotics according to (Disc- Diffusion Method) culture on (Cetrimide Agar) incubation at $\left(\mathbf{4 2 C}^{\circ}\right)$ for $(24 \mathrm{hr}$.)

The results have shown sensitivity of P.aeruginosa against Imipenem reached to $100 \%, 86.1 \%$ and $66.7 \%$ respectively these results were similar to several studies [21]. Ciprofloxacin has been reported as the second most effective drug against $P$. aeruginosa with sensitivity reached to $51.1 \%$ and agreed with a study done in Chandigarh-India [22]. Aztreonam was a monobactam $\beta$-lactam drug, It has excellent activity against Pseudomonas species but has a limited treatment option against Multidrug-resistant (MDR) strains of $P$. aeruginosa [23]. Aztreonam was used in the present study and it's sensitivity reached to $32.5 \%$. Piperacillin was active only against $13.9 \%$ of isolates. This finding was unique from other studies in which $57.4 \%$ of P.aeruginosa isolates susceptible to Piperacillin [24]. This study investigated that four ESBLs antibiotics the least effective against P.aeruginosa and the resistance reached to $86.0 \%$ and $88.3 \%$ for Cefotaxime and Ceftazidime while was $100 \%$ for both Ceftrixone and Cefepime $100 \%$. In the present study $93.0 \%$ of $P$. aeruginosa isolates showed resistance against antibiotics other than ESBLs such as, Gentamicin, this finding is similar to Iranian studythat shown more than $95 \%$ strains of $P$. aeruginosa were resistant to Gentamicin , Gentamicin is a cheap and easily available drug that is used extensively in general and hospital practice in clinically suspected Gram negative infections. This may be the main reason for the development of resistance in bacteria against this drug. P. aeruginosa has become increasingly recognized as an emerging opportunistic pathogen of clinical relevance, and several epidemiological studies confirmed its occurrence as a nosocomial pathogen and indicated that antibiotic resistance was increasing in clinical isolates toward most antibiotics [25].

\section{Recommendations}

Based on the findings of the present study, after reviewing the literature and many of the previous trials, the following recommendations can be suggested: Studying the changes in the pattern of bacterial colonized burns patients and environment burn units during the period of hospitalization. Using disinfectants in the hospitals to get rid of contamination and reduce the spread of antibiotic resistance.

\section{References}

1. Albornoz, C., Villegas, J., Sylvester, M., Pena, V. and Bravo, I. (2011). "Burns are more aggressive in the elderly: proportion of deep burn area/total burn area might have a role in mortality". Burns. 37(6): 1058-1061.

2. D'Avignon, L. and Hogan, BK. (2010). "Contribution of bacterial and viral infections to attributable mortality in patients with severe burns: an autopsy series". Burns. 36(6):773-779.

3. Alwash, S. (2013). "Study the effect of different concentration of ozonated water on MRSA isolated from clinical sample". M.Sc. Thesis/ College of Science/ University of Baghdad. 
4. Oncul, O., Acar, E., Turhan, A., Yeniz, V., Karacaer, E. and Yildiz, F. (2009). "Prospective analysis of nosocomial infections in a Burn Care Unit".Turkey. Burns. 758-764.

5. Gallagher, J., Williams-Bouyer, N. and Villarreal , C. (2007). "Treatment of infection in burns". In Herndon DN, ed, total burn care, $3^{\text {rd }}$ ed. Philadelphia: WB. Saunders. 136-176.

6. Guggenheim, M., Zbinden, R. and Handschin, A. (2009). "Changes in bacterial isolates from burn wounds and their antibiograms: A 20-year study (1986-2005)". Burns. 35: 553-560.

7. Birgy, A., Bidet, P. and Genel, N. (2012). "Phenotypic screening of carbapenemases and associated betalactamases in carbapenem-resistant Enterobacteriaceae". J. Clin. Microbiol. 50: 1295-302.

8. Alwan, J., Inam, J. and Aseel, M. (2011). "Bacterial isolation from burn wound infections and studying their antimicrobial susceptibility Kufa". J. for Vet. Med. Sciences. 2(1): 121-131.

9. Jabur, M. (2010). "Therapeutic efficacy of Lactobacillus acidophilus against bacterial isolates from burn wounds". North Am. J. of Med. Sciences. 2(12): 586-591.

10. Forbes, B., Sahm, D. and Weissfeld, A. (2007). "Bailey and Scott's Diagnostic Microbiology". International $12^{\text {th }}$ ed, Mosby, U.S.A.

11. Blazevic, D., Koepcke, M. and Matsen, J. (1972). "Quality control testing with disk antibiotic susceptibility test of Bauer-Kirby-Sherris-Turck”. Am. J. Clin. Pathol. 57(5):592-597.

12. Sharma, M. and Taneja, N. (2007). "Burns, antimicrobial resistance and infection control". The Indian J. of Med. Res. 126(6): 505-507.

13. Ulku, A., Serpil, E., Akcay, M., Fehmi, C. and Ayten, K. (2004). "The time-related changes of antimicrobial resistance patterns and predominant bacterial profiles of burn wounds and body flora of burned patients". Burns. 30: 660-664.

14. Japoni, A., Farshad, S. and Alborzi, A. (2009). "Pseudomonas aeruginosa: Burn Infection, Treatment and Antibacterial Resistance". Iranian Red Crescent Medical Journal. 11(3):244-253.

15. Taneja, N., Chari, P., Singh, M., Singh, G., Biswa, M. and Sharma, M. (2013). "Evolution of bacterial flora in burn wounds: key role of environmental disinfection in control of infection". Int. J. Burns Trauma. 3(2): 102107.

16. Naqvi, Z., Hashmi, K., Rizwan, Q. and Kharal, S. (2005). "Multi drug resistant Pseudomonas aeruginosa :A nosocomial infection threat in burn patients". Pakistan J. of Pharma. 22(2): 9-15.

17. Edwards, V. and Greenwood, J. (2003). "What's new in burn microbiology. James Laing Memorial Prize Essay 2000". Burns. 29(1): 15-24.

18. Lari, A., Bahrami, H. and Alaghehbandan, R. (1998). "Pseudomonas infection in Tohid Burn Centre, Iran". Burns. 24(7): 637-641

19. AL-Khazali, K. (2009). "Resistance of Pseudomonas aeruginosa and Staphylococcus aureus isolated from burns and wounds infections to antibiotics and some disinfectants". M.Sc. Thesis /College of Science/ ALMustansriyia University.

20. Al-Shamary, M. (2003). "A study of the effect of first degree burned skin extract on the host tolerance to gram negative bacteria". M.Sc. Thesis/ College of Sciencel University of Baghdad.

21. Mahmoud, A., Zahran, W., Hindawi, G., Labib, A. and Galal, R. (2013). "Prevalence of multidrug-resistant Pseudomonas aeruginosa in patients with nosocomial infections at a university hospital in Egypt, with special reference to typing methods". J. of Virol and Microbiol. 201: 1-13.

22. Kaushik, R., Kumar, S., Sharma, R. and Lal, P. (2001). "Bacteriology of burn wounds the first three years in a new burn unit at the Medical College Chandigarh". Burns 27(6): 595-597.

23. Douglas, M., Mulholland, K., Denyer, V. and Gottlieb, T. (2001). "Multi-drug resistant Pseudomonas aeruginosa outbreak in a burns unit an infection control study". Burns. 27(2): 131-135.

24. Gales, A., Azevedo, H., Cereda, R., Girardello, R. and Xavier, D. (2011). "Antimicrobial activity of doripenem against Gram-negative pathogens: results from INVITA-A-DORI Brazilian study". Braz, J. Infect. Dis. 15 (6): 513-520.

25. Sun, Z., Jiao, X., Peng, Q., Jiang, F., Huang, Y., Zhang, J. and Yao, F. (2013). “Antibiotic resistance in Pseudomonas aeruginosa is associated with decreased fitness".Cell Physiol Biochem. 31(23): 347-54. 